\title{
"Pretitude" e o Afroperspectivismo em Psicoterapia: Desafios para a Abordagem Gestáltica
}

\section{"Pretitude" and Afroperspectivism in Psychotherapy: Challenges for the Gestalt Approach}

\section{"Pretitude" y Afroperspectivismo en Psicoterapia: Desafíos para el Enfoque de la Gestalt}

\author{
Andrea dos Santos Nascimento* \\ Universidade Federal do Espírito Santo - UFES, Vitória, Espírito Santo, Brasil \\ Gabriela Faria de Souza** \\ Instituto Gestalt de São Paulo - Gestalt SP, São Paulo, São Paulo, Brasil \\ Maiara da Silva*** \\ Universidade Federal do Espírito Santo - UFES, Vitória, Espírito Santo, Brasil \\ Mário Silva de Oliveira**** \\ Universidade Federal do Espírito Santo - UFES, Vitória, Espírito Santo, Brasil
}

\begin{abstract}
RESUMO
Apresentamos a intervenção do projeto de extensão "Gestalt-Terapia, escuta e acolhimento psicológico de grupos", realizado desde 2018 por alunos extensionistas negros do Curso de Psicologia da Universidade Federal do Espírito Santo utilizando a abordagem Gestáltica. O objetivo é desenvolver a prática do acolhimento psicológico de grupos, para homens e mulheres negras, principalmente universitários. Para tanto, foram realizados 07 encontros no ano de 2018 (04 participantes) e 15 encontros no ano de 2019 (07 participantes), sendo 04 mulheres e 07 homens, com idades entre 19 e 45 anos. Os encontros aconteceram no Núcleo de Psicologia Aplicada em horário noturno. Os principais recursos terapêuticos são provenientes da expressão verbal e corporal, entretanto, músicas, vivências e atividades de colagens foram agregadas. Os resultados parciais indicaram que os encontros grupais proporcionaram cuidado e reconhecimento de si, do mundo e do outro, e melhora da autoestima na população assistida. Os participantes reconheceram muitos processos que interrompem as trocas afetivas, como resultado do racismo estrutural que a população negra brasileira vivencia. A consciência corporal e afetiva possibilitou uma reaproximação dos afetos positivos entre pessoas negras, de modo a reafirmar as características positivas dessa população.
\end{abstract}

Palavras-chaves: racismo, juventude negra, autoestima, autoimagem. 


\begin{abstract}
We present the intervention of the extension project "Gestalt-Therapy, listening and psychological reception of groups", conducted since 2018 by black extension students of the Psychology Course of the Federal University of Espírito Santo using the Gestaltic approach. The objective is to develop the practice of psychological group reception for black men and women, mainly university students. To this end, 07 meetings were held in 2018 (04 participants) and 15 meetings in 2019 (07 participants), 04 women and 07 men, aged 19 to 45 years old. The meetings took place at the Center for Applied Psychology at night time. The main therapeutic resources came from verbal and body expression, however, songs, experiences and collage activities were added. The partial results indicated that the group meetings provided care and recognition of self, of the world and the other, it also improved self-esteem in the assisted population. The participants recognized many processes that interrupt affective exchanges as a result of the structural racism that the black Brazilian population experiences. Body and affective awareness made it possible to re-approach positive affections among black people in order to reaffirm the positive characteristics of this population.
\end{abstract}

Keywords: racism, black youth, self-esteem, self-image.

\begin{abstract}
RESUMEN
Presentamos la intervención del proyecto de extensión "Terapia Gestalt, escucha y acogimiento psicológico de grupos", realizado desde 2018 por estudiantes negros extensionistas del Curso de Psicología de la Universidad Federal do Espírito Santo utilizando el enfoque Gestáltico. El objetivo es desarrollar una práctica de acogimiento psicológico de grupos, para hombres y mujeres negros, principalmente estudiantes universitarios. Para esto, fue realizado 07 encuentros en el año de 2018 (04 participantes) y 15 encuentros en el año de 2019 (07 participantes), siendo 04 mujeres y 07 hombres, con edades comprendidas entre 19 y 45 años. Los encuentros ocurrieron en el Núcleo de Psicología Aplicada en horario nocturno. Los principales recursos terapéuticos provenían de la expresión verbal y corporal, sin embargo, se agregaron la música, las experiencias y actividades de collage. Los resultados parciales indicaron que los encuentros grupales proporcionaron cuidado y reconocimiento de sí mismos, del mundo y del otro, y mejoraron la autoestima de la población asistida. Los participantes reconocieron muchos procesos que interrumpieron, destacándose los intercambios afectivos como resultado de un racismo estructural que la populación negra brasileña experimenta. La consciencia corporal y afectiva posibilitó una reaproximación de los afectos positivos entre personas negras, a modo de reafirmar las características positivas de esta populación.
\end{abstract}

Palabras clave: racismo, juventud negra, autoestima, autoimagen.

"Pretitude" é a junção das palavras preta e atitude, uma provocação e um convite para as pessoas negras serem protagonistas ativas de suas histórias. Ressignificar lugares e existências, ocupando o lugar de cidadão, de sujeito de direitos, de pertencimento e de cura, frente ao racismo institucional e estrutural (Almeida, 2018) de mais de 500 anos de história brasileira. O convite que agora fazemos é ir ao encontro amoroso e cuidadoso de pessoas de pele preta, àquelas que 
ainda sofrem os efeitos da escravização no Brasil (Conselho Federal de Psicologia, 2017; Mbembe, 2018).

Nesse contexto, o que tem feito os psicólogos humanistas, mais especificamente os gestalt-terapeutas, por um humanismo que seja latino e que atenda às características da miscigenação brasileira, de um povo colonizado, de um povo indioafrodescendente? Como defender um "fazer psi" que seja holístico, contextual, crítico, organísmico e amoroso, em busca da superação das interrupções de contato, intra e interpessoais, por meio da abordagem humanista, existencial e fenomenológica que é o cerne, e a alma, da Gestaltterapia de Perls, Hefferline e Goodman (1997)?

Tendo esse desafio do encontro com a diferença como figura, e o contexto social como fundo, a abordagem gestáltica, entendida nesse trabalho também como Gestalt-terapia, apresenta-se como uma abordagem alicerçada em várias bases filosóficas e teóricas (Frazão \& Fukumitsu, 2013) que possui uma rica quantidade de conceitos próprios que atendem a provocação que o tema da desigualdade racial nos convoca a enfrentar. Para apresentação deste trabalho, fundamentamo-nos no diálogo genuíno e na aceitação das diferenças como uma aposta de vida e de cura, tal como apontam de Hycner e Jacobs (1997), Ribeiro (1994) e na inclusão de Yontef (1998) para as questões complexas da existência humana. Escuta atenta, fenomenológica e empática também foram ferramentas essenciais para proporcionar ao psicoterapeuta a validação dos afetos que surgiram.

\section{Fenomenologia, psicoterapia dialógica e cura}

Para Ribeiro (1994) uma escuta baseada no método fenomenológico significa atentar-se apenas à realidade que se apresenta e trabalhar a partir dela. O fenômeno é o que comparece, é a figura que nos conduzirá em direção à totalidade.

Uma postura dialógica e, também, fenomenológica aponta para a importância do vínculo estabelecido entre terapeuta e cliente (Buber, 2001; Hycner \& Jacobs, 1997) na relação que se coloca durante o acolhimento, no nosso caso, no trabalho em grupo tal como descrito inicialmente por Tellegen (1984) e Ribeiro (1994). O relacionamento com o psicoterapeuta pode favorecer que o grupo apresente de forma genuína seus conflitos, medos, expectativas e apostas (Fadel \& Pinheiro, 2015).

O trabalho em grupo, tal como apresentado por Tellegen (1984) e Ribeiro (1994), e voltado para as minorias sociais, especificamente, tem se demonstrado um desafio para a abordagem gestáltica. Para fins desse estudo, adotaremos o entendimento de Hernandez, Accorssi e Guareschi (2013), no qual afirmam que minorias sociais 
são grupos que não se definem por sua inferioridade quantitativa, e sim por sua condição de marginalização e discriminação devido a aspectos sociais, econômicos, culturais, físicos ou religiosos. Este artigo traz no cerne de sua discussão a população negra enquanto uma minoria social que, em decorrência de seus fenótipos, vivencia processos de exclusão e preconceito.

Historicamente, fala-se muito pouco sobre gestalt e minorias sociais, mais restrita ainda é a discussão sobre raça e atendimento psicoterapêutico voltado para pessoas negras (Oliveira, 2008) por essa abordagem. Neste caso, compreendendo a importância das relações interpessoais - permeadas por afetos na qualidade de emoções, sentidos, vivências, valores e crenças - que muitas vezes são oprimidas e silenciadas em cada um e em todos, de formas e níveis diferentes e que acabam por refletir um modo de ser (individual e ao mesmo tempo coletivo) em uma determinada cultura, classe, raça e gênero -, o trabalho com grupos ganha um destaque especial. Neste contexto, o grupo torna-se uma rede de apoio desenvolvendo e ampliando seus próprios horizontes, trabalhando suas questões, sem esquecer os conflitos que atravessam a todos e cada um, de maneira particular.

Em Gestalt-terapia, portanto, preconiza-se que no relacionamento terapêutico a experiência do outro seja acolhida sem julgamentos, análises ou interpretações, sem que se perca o sentido da própria presença distinta do terapeuta ou facilitador, no caso do grupo. Yontef (1998) vai chamar esse processo de inclusão da experiência imediata do participante de forma a proporcionar um ambiente de segurança, possibilitado pela condução fenomenológica, onde tornase possível a awareness de cada participante e do grupo enquanto totalidade. Cabe ao psicoterapeuta da abordagem gestáltica compreender o fenômeno tal como ele se apresenta e facilitar para o grupo, lado a lado, uma ressignificação de sua própria experiência (Fadel \& Pinheiro, 2015).

O grupo de acolhimento para homens negros e mulheres negras, à luz da abordagem gestáltica, tem se configurado como uma possibilidade de escuta no qual o desenvolvimento de uma observação paciente, de intervenções cuidadosas e respeitosas, de uma leitura humilde e compartilhada do conteúdo acessado durante os encontros, têm sido elementos priorizados. Essa proposta atende ao que instrui Ribeiro (1994) em relação ao trabalho em grupo em Gestalt-terapia.

O Conselho Federal de Psicologia (2017) enfatiza que é imprescindível que os profissionais de psicologia compreendam as relações raciais existentes na sociedade e que o racismo é causador de sofrimento psíquico, uma vez que a população negra ao ser discriminada e marginalizada, é assolada por sentimentos de inferioridade, um 
constante estado de alerta e é vítima de violências físicas e emocionais.

Por meio dessa proposição, evidencia-se que considerar a dimensão raça no acolhimento psicológico - e por isso proporcionar um espaço de escuta para questões dos sujeitos negros - é, antes de tudo, considerar a integralidade do sujeito. É comprometer-se com o trabalhoso e doloroso processo psicológico de tomada de consciência do racismo por parte dos homens negros e mulheres negras.

Tal como pontuou Oliveira (2008), a experiência de acolhimento para pessoas negras salienta a importância de romper com a tendência de invisibilização da raça no cuidado psicológico. Como expõe Bento (2002a), estar inserido em uma sociedade que enfatiza o pertencimento a um grupo racial, torna o desenvolvimento da identidade racial um processo inevitável. Em decorrência do racismo, a forma que esse processo ocorre nas pessoas negras atrela-se a dores e a sofrimentos. Kilomba (2010) discorre que o racismo associa a imagem do negro a aspectos pejorativos, tais aspectos interferem de forma intensa na formação da identidade da pessoa negra, gerando sentimento de culpa e vergonha.

O espaço grupal fenomenológico, dialógico e acolhedor pode proporcionar um ambiente em que as dores diversas e o sofrimento psíquico vivenciado pela população negra podem ser expressos, compartilhados e coletivamente articulados. O sofrimento presente no cotidiano das pessoas negras, como afirma Kilomba (2010), não tem suas raízes apenas em experiências individuais e particulares do sujeito negro, mas sim em uma experiência que é coletiva e comum à população negra: o contato com a brutalidade do racismo, a partir de uma lógica segregacionista que privilegia a branquitude. Neste sentido, a cura dos efeitos do racismo na subjetividade negra, não é só do cliente, mas também do terapeuta.

\section{Por uma afroperspectiva na psicologia gestáltica, que proposta é essa?}

Como podemos fazer um acolhimento em grupo, tendo por base a abordagem gestáltica, que não seja atravessada pela leitura detalhada de intelectuais negros e negras que sofreram e ainda sofrem com anos de silenciamento impostos pela branquitude? Veiga (2017), psicólogo, pesquisador e militante do movimento negro, provoca a psicologia a se descolonizar, que significa colocar a própria subjetividade negra como referência para a prática clínica de acolhimento às pessoas negras.

Nesse sentido, é preciso colocar em suspensão (e suspeição) todo o conhecimento branco, patriarcal e europeu a respeito dos diferentes modos de ser e estar no mundo. Para Veiga (2017) somente no 
encontro entre subjetividades negras que o processo de cura se torna possível, tendo em vista os traumas provocados pelo racismo. Assim destaca o autor que a:

Clínica e política são inseparáveis na Psicologia Preta porque o sofrimento de pessoas negras não é da ordem da neurose, da ordem do privado, mas é sim produzido e mantido social e historicamente através de dispositivos políticos que desde a abolição trabalham para exterminar a população negra. A cura dos traumas do racismo e a luta pela igualdade racial caminham lado a lado na prática profissional do (a) Psicólogo (a) Preto (a). A dor dos pacientes é entendida para além do sofrimento psíquico, mas também como um problema político. É neste sentido que clínica e política se fundem produzindo, nos psicólogos e nos pacientes, deslocamentos e reparações aos danos que a diáspora e o racismo causaram. (Veiga, 2017, "Uma Psicologia Preta só é Feita por Psicólogos(as) Pretos(as)", para. 5).

Psicologia Preta, para Veiga (2019), tem como ponto de partida a valorização e estudo de narrativas pretas, problematizando as narrativas brancas hegemônicas. "Dizemos não a uma certa psicologia, branca demais para acolher e tratar dos efeitos do racismo em nossas subjetividades, e nos aprofundamos no estudo para o desenvolvimento de uma Psicologia Preta no Brasil." (p. 4).

No Brasil, por exemplo, Souza (1983) apresentou de forma autobiográfica e inquietante um debate sobre identidade negra, racismo e, consequentemente, o sofrimento psíquico advindo da discriminação e da exclusão social. Após 19 anos de sua escrita, Carone e Bento (2002) pela ótica da Psicologia Social, estudaram a branquitude como foco de análise, mostrando os mecanismos de manutenção de status quo racial perante as demais. Ainda de acordo com Bento (2002b), branquitute pode ser entendida como uma lógica de dominação ideológica, na qual a raça branca é tida como o "modelo universal de humanidade." (p. 25).

Nesse espectro de escrita de intelectuais negros e negras que agregaram aos estudos acerca do sofrimento psíquico e da subjetividade negra destacamos: Almeida (2018); Moreira (2018); Davis (2017, 2018); Mbembe (2018); Berth (2019); Ribeiro (2017), entre outros que podem ser encontrados ao longo desse texto. Tais autores foram centrais para o desenvolvimento e aperfeiçoamento constante do acolhimento de pessoas negras em diálogo com a abordagem gestáltica.

A filósofa Djamila Ribeiro (2017) trouxe maior proximidade com o conceito de "lugar de fala", muito utilizado nos debates em sala de aula e nos movimentos sociais da negritude universitária. A autora 
evita com maestria termos academicistas para a explicação do conceito, mostrando de forma didática de onde ela própria fala. Interessante destacar que é preponderante em toda a reflexão da autora o diálogo com autoras feministas negras, tanto brasileiras, quanto estadunidenses, fazendo um histórico do movimento feminista negro, destacando a opressão das mulheres negras e de que forma o lugar de fala vocaliza e dá visibilidade aos diversos tipos de feminismo.

Lugar de fala para a autora não é individual, mas estrutural, social e contextualizado, mostrando a importância de vocalizar grupos sociais historicamente marginalizados, como é o caso das mulheres negras. Só quem pode dizer do seu sofrimento é quem sofre, ao mesmo tempo em que um sofrimento não é menor que o outro, mas alguns sofrimentos não são comparáveis entre si, principalmente em ambientes onde imperam a desigualdade social, de classe e de gênero. Para a autora é preciso reconhecer que as narrativas são construídas tendo por base a realidade do grupo social que o enuncia (Ribeiro, 2017), e isso significa que nem todos têm igual acesso aos espaços de narrativas privilegiadas. A autora defende que se questione uma suposta neutralidade e objetividade no conhecimento que ainda é produzido, principalmente as epistemologias produzidas pela branquitude. Lugar de fala é uma forma de permitir que as narrativas emudecidas compareçam ao cenário político e social.

Uma vez entendido que todos têm direito a fala, desde que localizados socialmente e que respeite os diversos modos de subjetivação, era preciso entender o conceito de empoderamento. Berth (2019) discute que para que haja empoderamento é preciso que aconteça uma transformação social profunda. Empoderar-se não se trata de um voo solo, ninguém se empodera sozinho, o que é essencial para o trabalho em grupos, mas que antes de tudo é um processo orgânico entre o individual e o coletivo, um instrumento de luta por igualdade, emancipação, aceitação da sua imagem, estética, cultura e história, rompendo com a realidade opressora que vem sendo imposta como natural.

O empoderamento que seguimos neste trabalho não visa retirar poder de um para dar a outro a ponto de se inverter os polos de opressão, e sim de uma postura de enfrentamento da opressão para eliminação da situação injusta e equalização de existência em sociedade. (Berth, 2019, p. 23).

Desse modo, o racismo estrutural age de forma silenciosa, ardil e despotencializante. Almeida (2018) entende o racismo como modos de tratamento destinados a pessoas alocadas em grupos raciais específicos, ou seja, por meio da discriminação racial. Essa prática encontra fundamento nas relações de poder que se estabelecem 
entre os grupos raciais, uns com vantagens sobre outros, devido a essa discriminação racial estruturada, que se manifesta ainda nos diversos espaços de poder, sejam econômicos, institucionais ou políticos.

Institucionalmente, o racismo privilegia determinados grupos de acordo com a raça. Instituições regulamentam normas que determinam modos de pensar, preferências, valores, ou seja, determinam práticas comportamentais e afetivas. Em um contexto de relação de poder, por meio de regras que são naturalizadas pela maioria, a hegemonia "natural" de um grupo sobre o outro se torna possível e mantém seus interesses sociais, políticos e econômicos garantidos, "as instituições são a materialização das determinações formais na vida social." (Aldeida, 2018, p. 30). A mass media possui, para Almeida (2018), um papel fundamental, assim como a cultura e a escola, pois são instituições que, por meio de uma perspectiva racista, moldam o imaginário social em "uma rede de sentidos compartilhados coletivamente." (p. 53).

Freire (1996), em Pedagogia da Autonomia, convoca a sociedade para um processo de cura em relação aos seus modos de existência excludentes. Em palavras que não cabem relativismos:

Não me venha com justificativas genéticas, sociológicas ou históricas ou filosóficas para explicar a superioridade da branquitude sobre a negritude, dos homens sobre as mulheres, dos patrões sobre os empregados. Qualquer discriminação é imoral e lutar contra ela é um dever por mais que se reconheça a força dos condicionamentos a enfrentar. (p. 25).

Apropriando-nos do nosso lugar de fala, de produção de saberes científicos (ainda que elitistas) somos estimulados a exercer o que Freire (1996) denomina como "curiosidade epistemológica." (p. 54). Autoanálise, reflexão, contestação de quem somos e o que queremos, em uma perspectiva menos europeia e mais afrobrasileira.

A cura do outro, e nossa também, só se dará pelo enfrentamento das práticas racistas compreendendo a própria subjetividade da pessoa negra e, neste sentido, esse trabalho se justifica social e cientificamente, pois além de propiciar aos alunos de psicologia uma intervenção humanista com grupos de minorias sociais, é revolucionário no que tange as necessidades e particularidades desse grupo específico. No campo acadêmico, a discussão e a reflexão da proposta que apresentamos chega a nos apontar para o que chamamos intuitivamente de "psicologia gestáltica em afroperspectiva". Entendemos, tal como Nogueira (2011a, 2011b), a afroperspectiva como um referencial, prático e filosófico, que é construído a partir das pessoas africanas, afrobrasileiras e afrodescendentes em diáspora. Neste sentido, a pessoa negra não 
está à margem, nem é um recorte, encontra-se no centro de nossa análise.

O objetivo geral dessa intervenção é propiciar, nas dependências da universidade pública, um grupo de acolhimento psicológico para homens negros e mulheres negras, com foco principal em universitários. Entende-se que essa intervenção também possui outros objetivos, que em muitos momentos tornam-se figuras, tais como: reconhecer e cicatrizar as feridas psíquicas promovidas pela dominação colonial branca europeia; propor uma atitude preta frente à branquitude dominante nos espaços sociais, principalmente 0 universitário, e oferecer um espaço de discussão e afirmação da identidade negra.

\section{Apresentando o método do projeto de extensão}

No final de 2017 foi apresentado para o Departamento de Psicologia, a pedido de um grupo de alunos, um projeto de extensão para acolhimento das minorias sociais sob os cuidados da professora responsável pela cadeira de Gestalt-terapia. Era interesse propor um grupo de acolhimento psicológico para pessoas negras, tendo em vista o grande número de jovens que sofriam preconceito dentro da universidade devido às ações afirmativas, tal como demonstrado nos estudos de Guimarães (2003), Gonçalves e Ambar (2015).

Uma vez aprovado o projeto, foram selecionados os extensionistas voluntários para dar início aos trabalhos e foi convidada uma psicóloga gestalt-terapeuta que atuava em consultório particular, tendo como público também as pessoas negras. O critério de seleção dos alunos era: ter realizado a disciplina optativa de Gestalt-terapia; ter interesse no trabalho psicoterapêutico em grupos; se identificar como negro/negra ${ }^{1}$; estar finalizando quarto ano de graduação em Psicologia e ter afinidade com a abordagem gestáltica.

Para que o trabalho fosse iniciado, além do conhecimento em Gestaltterapia, era importante a leitura e discussão dos textos escritos por intelectuais negras e negros. Acentuamos a diferença entre os gêneros, pois existem diferenças de temáticas abordadas entre os homens negros e as mulheres negras, entre eles destacamos a solidão da mulher negra, o feminismo e o empoderamento da mulher negra. Esta parte foi imprescindível para a escuta acolhedora e compreensão dos afetos que compareceram no grupo, com atenção às diferenças entre os gêneros (e orientação sexual também).

Os encontros do grupo são abertos, no qual as pessoas podem entrar e sair a qualquer momento. Outro destaque é que o grupo acolhe tanto a jovens universitários, quanto a comunidade externa. Tem-se investido na construção de um espaço em que as pessoas possam se 
envolver em seus processos de mudança, responsabilizando-se de forma livre e autônoma por isso.

Foram realizados 07 encontros no ano de 2018 e 15 encontros no ano de 2019, com um total de 07 participantes: 02 mulheres e 05 homens, com idades entre 19 e 45 anos. Todos os encontros aconteceram no Núcleo de Psicologia Aplicada (NPA/Ufes) em horário noturno com duração máxima de duas horas semanais. A supervisão era realizada em outro dia e horário com a presença da coordenadora do projeto e da psicóloga externa convidada. Os principais recursos terapêuticos utilizados foram a expressão verbal e corporal, contudo, em muitos momentos adotamos estratégias diversas como músicas, experimentos, vivências e atividades de colagens de forma a enriquecer e proporcionar um maior contato com as questões que foram colocadas pelo grupo.

Os diários de campo eram preenchidos pelos extensionistas a cada encontro, assim como o prontuário de grupo, cujas anotações, sentimentos e percepções eram debatidos em supervisão. Esses documentos propiciaram a escrita deste artigo, mantendo o sigilo e a privacidade dos participantes. Todo participante, ao ingressar no grupo, era informado sobre as supervisões semanais com a coordenadora e a psicóloga convidada, além da possibilidade de que a vivência do grupo fosse transformada em trabalhos de congressos, capítulos de livros ou artigos científicos para impulsionar mais pesquisas e intervenções na área da Gestalt-terapia voltadas para a saúde mental da população negra.

A seguir, apresentaremos as principais discussões que ocorreram nos encontros. Todos os participantes receberam nomes fictícios de afrobrasileiros e afrobrasileiras que lutaram pela liberdade e pelo fim da escravização no Brasil.

\section{Resultados e discussão}

Historicamente, a população negra tem enfrentado e resistido ao constante silenciamento de seu discurso e de suas dores (Kilomba, 2010). Os participantes do grupo relataram a ausência de espaços seguros para expressão do sofrimento causado pelo racismo, no qual as dores psíquicas não serão deslegitimadas, ou até mesmo utilizadas para subjugação do sujeito em sofrimento:

"Se você se apresenta como frágil [com dores] diante de alguém que não ocupa essa posição, tal pessoa pode tentar te dominar de alguma forma." (Jacimba Gaba, 19 anos).

"O sofrimento da pessoa negra ainda é visto como no período da escravidão, algo naturalizado, que não comove." (Zumbi dos Palmares, 22 anos). 
Foi narrado no grupo que, frequentemente, as pessoas pretas expõem nos ambientes que frequentam suas dores oriundas do racismo, todavia, estas são constantemente minoradas e ignoradas. Em contrapartida, quando uma pessoa branca é a enunciadora de tais questões, esta é escutada:

"Eu sei que elas [alunas brancas] querem ajudar, mas me incomoda quando eu falo e ninguém escuta e quando uma menina branca da minha sala fala e todo mundo ouve. Pô, a experiência é minha, eu quero dizer." (Anastasia, 22 anos). "Quando um negro fala sobre seu sofrimento ninguém ouve, mas se for uma pessoa branca geralmente escutam." (Jacimba Gaba, 19 anos).

Um espaço de escuta e acolhimento para pessoas negras é por si desafiador, pois convoca os participantes, incluindo os estudantes de psicologia, a romperem com essa lógica massacrante de silenciamento, processo doloroso para todos os envolvidos. Neste sentido, os estudantes ocuparam o papel de facilitadores, mas também de participantes ativos (Tellegen, 1984; Veiga, 2017) da vivência grupal, sendo impossível não participarem organicamente dos afetos interpessoais compartilhados. Transgredimos, desta forma, com a ideia do terapeuta isento a cultura racializada na qual ele mesmo, na qualidade de pessoa negra, também é vítima.

Os processos de tomada de consciência do racismo, assim como os afetos gerados por tais processos compuseram desde o início as discussões do grupo. Os movimentos do grupo evidenciaram que falar sobre racismo envolve não apenas entrar em contato com 0 sofrimento e efeito desse sistema de opressão em si mesmo, como também possibilita refletir acerca da influência do racismo na estruturação da sociedade e na forma que as relações se estabelecem. É colocar em análise as hierarquias que são sustentadas pela imposição do privilégio branco, as vantagens usufruídas pela branquitude e os efeitos desses processos no cotidiano das pessoas negras. Durante os encontros, os participantes compartilharam diversas situações vivenciadas ao longo de suas vidas que foram marcadas pela discriminação, as quais foram elaboradas depois da tomada de consciência do racismo:

"Eu me esforço muito, sou a primeira da turma, moro longe, mas não falto aula, mesmo se for em dia de chuva. Sou capaz de ir em dia de greve de ônibus." (Anastasia, 22 anos).

"Não posso falhar, tenho que ser 10 pelos meus, porque se eu falhar alguém pode morrer. Geralmente os seguranças que nos seguem são negros também. São homens que estão inseridos 
em comunidades, nas quais a juventude está envolvida com a criminalidade e a associação da imagem de qualquer jovem negro com o crime é algo inevitável." (Dandara, 25 anos, Educadora social).

Comportamentos inicialmente considerados aspectos individuais, tais como elevada autocrítica, busca por alto desempenho escolar, problemas com a própria imagem, foram ressignificados no contato com as narrativas de outros participantes, percebendo com isso, a influência massiva do racismo nesses corpos, tal como também aponta Almeida (2018) quando discorre do impacto social do racismo institucional nas pessoas negras.

Durante os encontros, os participantes identificaram em suas trajetórias a influência de discursos racistas que inferiorizam a imagem das pessoas negras, os entraves impostos pelo racismo que dificultam a inserção do negro em diversos espaços do tecido social, o que exige que o esforço de uma pessoa preta seja maior que de uma pessoa branca em diversos aspectos do cotidiano, como também apontado nas reflexões de Almeida (2018), Berth (2019), Ribeiro (2017) e Moreira (2018).

Foi discutido no grupo que além dos entraves reais resultantes de uma estrutura racista que impede que pessoas pretas ocupem determinados lugares, une-se a isso a consolidação no imaginário social de que alguns lugares não são propícios para as pessoas negras ocuparem (Guimarães, 2003; Gonçalves e Ambar, 2015), naturalizando, desta forma, a ocupação de subempregos por pessoas negras. A discussão suscitada no grupo enfatizou que a crítica não diz respeito a uma desvalorização de determinadas profissões associadas às práticas de servir, as quais são extremamente importantes para o funcionamento da sociedade, e sim a naturalização de que apenas determinados grupos devem, indubitavelmente, ocupar esses cargos. Um trecho da música "Da Lama", interpretada por Tássia Reis e Stefanie ${ }^{2}$, foi usada como referência pelos participantes em relação a essa discussão: "É ver que pra nós a chance nunca sai do zero". Nesta música, foi explicado que a cantora fala sobre o assassinato do irmão de uma amiga e, deste modo, aponta para a problemática do racismo estrutural brasileiro e da discriminação, que tem como consequência o extermínio da juventude negra (Mbembe, 2018).

"Nunca nos dizem que podemos chegar onde queremos. E quando chegamos ainda nos sentimos inadequados em alguns espaços." (Zumbi dos Palmares, 22 anos).

"Se eu fosse mais branco abriria um restaurante." (Jacimba Gaba, 19 anos - refletindo sobre como o racismo estrutural aparece na fala desesperançosa de seu irmão). 
A expressão de afetos foi um tema recorrente no grupo. Vários participantes narraram a dificuldade de expressar seus sentimentos e vivenciar as emoções no momento em que acontecem. A demonstração de afeto foi, por vezes, associada por eles a vulnerabilidade e a fraqueza. Foi discutido que a demonstração de afetos é um processo socialmente aprendido, e que no caso das pessoas negras esse processo não ocorre da mesma forma que nas pessoas brancas. Um dos participantes relata:

"Desejo conseguir expressar-me, não precisar 'engolir as coisas', mas tenho receio de demonstrar sentimentos, emoções e afetos e mostrar-me vulnerável, fraco. Expor-me ao outro [demonstrar afetos] pode ser danoso, faz com que eu me sinta vulnerável." (Dragão do Mar, 24 anos).

A recusa em sentir, como colocado por Mercy (como citado em hooks, 2006), provoca um empobrecimento emocional marcado por um entorpecimento psíquico. Entrar em contato com os afetos é importante para que os processos que usam a energia de tais afetos de forma criativa sejam fortalecidos. hooks (1994) discorre que a relação das pessoas negras com a expressão de afetos pode ser relacionada com a escravização. O modelo de sociedade estruturado na opressão das pessoas negras condicionou essa população a contenção de seus sentimentos.

A autora relata que durante a escravização, a repressão das emoções determinava muitas vezes a sobrevivência das pessoas escravizadas. Mesmo após o término formal da escravização, a repressão dos sentimentos como estratégia de sobrevivência continuou a ser um aspecto da vida dos negros. O racismo e a supremacia dos brancos permaneceram após a abolição da escravatura e as barreiras emocionais foram mantidas pelo povo negro.

Diante desse cenário, assim como propõe hooks (2006), é urgente a necessidade de fortalecer modos de vida que vão além da sobrevivência, é necessário fomentar condições para que as pessoas negras possam viver plenamente. E para isso, o reconhecimento das necessidades emocionais como algo merecedor de atenção é fundamental para pessoas negras.

Pensando na diferença de perspectivas de vida para homens negros e mulheres negras, mesmo que ambos sejam hipersexualizados culturalmente (Conselho Federal de Psicologia, 2017), as mulheres possuem um diferencial, pois delas se espera uma vida de abnegação e cuidado dedicado aos filhos e da casa das pessoas brancas. Para a participante Dandara, 25 anos, a mulher negra é estereotipada socialmente como "boa de serviço pesado, não foi feita para falar de seus desejos e vontades, muito menos de felicidade que não seja o samba". Há um consenso silencioso e socialmente aceito, e 
estimulado, de que não existe possibilidade de realização e de felicidade para essas mulheres que não esteja no rebolado e nas funções domésticas da branquitude. Já a participante Jacimba Gaba (19 anos), assim explica como seu futuro the era apresentado na adolescência: "Quando você tiver 16 anos já vai estar trabalhando em casa de família". Romper com essa lógica ainda permanece como um desafio para esse grupo.

A relação com o outro foi uma questão de destaque no grupo. Os participantes narram que confrontar-se com o olhar do outro causa desconforto e amedronta. Geralmente, esse olhar é marcado pela avaliação e julgamento pautados em ideais racistas. Os participantes discutiram que, de forma geral, esse olhar depreciador parte de pessoas brancas em ambientes que a presença de pessoas negras não é vista com naturalidade:

"Sei que devido ao meu cabelo [crespo] sou associado com estereótipo de criminoso." (Dragão do Mar, 24 anos).

"Sinto-me desconfortável em ambientes frequentados majoritariamente por pessoas brancas, pois em tais ambientes, geralmente, minha presença não é vista com naturalidade. No meu antigo trabalho, por exemplo, não conseguia ser eu mesma. Era calada e não conseguia me expressar de forma espontânea." (Jacimba Gaba, 19 anos).

Dessa forma, estar em ambientes com pessoas negras é mais confortável, pois o reconhecimento recíproco torna a relação mais leve e transmite a sensação de honestidade, horizontalidade e ausência de julgamento baseados em estereótipos, o que também é apresentado por Veiga (2017). Os participantes perceberam que muitas vezes a privação de contato com determinados grupos é uma estratégia de defesa, um mecanismo de proteção diante da violência do racismo:

"Uma estratégia de enfrentamento é a aproximação de pessoas pretas, para fortalecimento da autoimagem e autoestima, para conseguirmos estar em ambientes que são desconfortáveis." (Luis Gama, 23 anos).

"Gostaria de entrar nos lugares e ver mais pessoas pretas (Luis Gama, 23 anos) ou "Nunca estive em um lugar com tanta gente preta" (Dragão do Mar, 24 anos), são exemplos que também compõem o conteúdo de não-pertencimento e inadequação, que só é possível se deixar tocar a partir da escuta atenta dos afetos da população negra, discursos esses que geram sofrimento e uma alienação de si. 
A relação com a imagem e com o próprio corpo foi um elemento percebido como conflituoso pelo grupo. Alguns relatos evidenciaram um progressivo processo de aceitação, afirmação e valorização da estética negra, tais como:

"Meu pai não aceita meu cabelo, diz que eu fico feio com ele grande, mas eu não raspo, é bonito assim." (Zumbi dos Palmares, 22 anos).

"Eu não pegava sol, porque eu não queria ficar mais preta. Uma vez fui a praia e na volta minhas primas falaram que eu estava mais preta, eu corri para minha mãe chorando e perguntando se eu estava mais preta. Minha mãe me acalmou dizendo que não havia como ficar mais preta. Eu não tomava café com medo de ficar mais preta." (Jacimba Gaba, 19 anos).

"Teve ocasiões em que eu estava tão cansado que só conseguia pensar em como queria ser branco, pois as coisas seriam mais fáceis." (Zumbi dos Palmares, 22 anos).

Foi intensamente discutido a complexidade desse processo, que é marcado por estereótipos que depreciam a estética e cultura negra impondo ideais de beleza brancos e eurocêntricos (Gomes, 2017). Ao longo dos encontros foi possível perceber no grupo movimentos com o propósito de superação do pensamento racista, dos estereótipos limitantes de ausência de beleza impostos por esse ideal, além de uma ressignificação da própria autoimagem e da imagem de outras pessoas negras que convivem ao redor.

"Eu sempre fiz chapinha, alisava mesmo. Depois queria meus cachos, incentivada por uma prima. Foi difícil, hoje eu amo meus cabelos. Tem muitos produtos atualmente, muita coisa mesmo." (Anastásia, 22 anos).

"Eu cortava meu cabelo careca, agora assumi que ele é crespo. Meus pais não aceitaram, falavam que era feio, mas eu gosto assim." (Zumbi dos Palmares, 22 anos).

"O processo de aceitação de minha imagem, de considerar-me bonita fez com que passasse a considerar de forma mais intensa os traços negros bonitos." (Jacimba Gaba, 19 anos).

"Reconhecer a própria beleza é o primeiro passo para reconhecer a beleza do semelhante." (André Rebouças, 19 anos).

Gomes (2017) afirma que o corpo negro deve ser entendido não apenas em sua existência material, mas também em sua dimensão simbólica e política. O movimento percebido no grupo reflete os efeitos do processo mais amplo descrito pela autora, que descreve que aos poucos ter um corpo negro no Brasil e expressar a negritude 
associa-se a uma afirmação positiva de expressão de cultura e afirmação de identidade. Sendo assim, o desenvolvimento de uma relação de afirmação com a própria imagem e corpo significa, para uma pessoa negra, afirmar-se politicamente e resistir à opressão branca. Marca o rompimento com uma corporeidade regulada pelos processos de colonização e pela escravização.

\section{Considerações finais}

Percebe-se que os encontros em grupo têm proporcionado aos participantes um ambiente de cuidado e de reconhecimento de si, no qual um modo de relacionamento consigo e com os outros, diferenciado dos que são regidos pela lógica colonial e pelo racismo, tem sido fortalecido. Tal como salienta hooks (1994) em uma sociedade em que a supremacia branca prevalece, as vidas das pessoas negras são permeadas por questões que resultam na interiorização do racismo e de um sentimento de inferioridade. Assim, articular um espaço de acolhimento para essa população busca, justamente, romper com esses processos que massificam o corpo, a estética, os afetos e o contato desse grupo.

$\mathrm{Na}$ prática terapêutica em grupo, partindo de uma postura acolhedora, dialógica e fenomenológica, se almeja o cuidado com o outro na sua totalidade, cuja ênfase está na relação, sem ignorar os aspectos culturais, valores morais e éticos que atravessam essas relações. A produção de sentidos que desse encontro decorre, se faz tanto no nível individual, quanto grupal. Assim, a psicoterapia em grupo enfatiza a vivência do encontro e depois se ancora na compreensão do todo, desencadeada pelo próprio processo. As considerações dos autores aqui citados dão maior destaque ao momento presente e a abertura ao encontro, que só é possível quando percebemos o quão incrivelmente estamos entrelaçados.

Apesar das limitações deste estudo, pois muitos conceitos da abordagem gestáltica poderiam ter sido abordados e aprofundados, tais como self, aqui-e-agora, interrupções do contato, autorregulação organísmica, entre outros, fizemos uma escolha ao focar na questão da relação grupal, na postura de escuta fenomenológica e dialógica do terapeuta que propicia o aparecimento de questões existenciais complexas do cotidiano das pessoas negras. Há uma gama de possibilidades que ainda podem ser aprofundadas pelos pesquisadores da área, no que se circunscreve a problemática de como o racismo adoece e como a abordagem gestáltica pode intervir. Além disso, consideramos que o presente texto é um instrumento possível para nos aproximarmos de forma mais autêntica e congruente das vivências e do sofrimento psíquico de pessoas negras. 
É desafiante, em meio a tantas violências, um fazer radical e amoroso no enfrentamento do racismo, de forma a fortalecer uma "prática psi" que não desqualifica, generaliza ou minimiza o sofrimento humano e o adoecimento mental oriundo da opressão que a população de negra sofre. Isso só tem sido possível a partir do momento em que se abre a possibilidade do diálogo e da inclusão na prática da abordagem gestáltica com os saberes construídos a partir dos autores e das autoras que vivenciam e denunciam o racismo cotidianamente, e de seus mais diversos modos.

Indiscutivelmente, a vida que existe em nós, e em cada um de nós, não pode ser domada, excluída e violentada! A vida insiste e resiste! Por mais pretitudes!

\section{Referências}

Almeida, S. (2018). O que é racismo estrutural? Belo Horizonte, MG: Letramento.

Bento, M. A. S. (2002a). Branqueamento e branquitude no Brasil. In I. Carone \& S. A. M. Bento (Eds.), Psicologia social do racismo: estudos sobre branquitude e branqueamento no Brasil (pp. 2557). Petrópolis, RJ: Vozes.

Bento, M. A. S. (2002b). Branquitude: o lado oculto do discurso sobre o negro. In I. Carone \& S. A. M. Bento (Eds.), Psicologia social do racismo: estudos sobre branquitude e branqueamento no Brasil (pp. 147-162). Petrópolis, RJ: Vozes.

Berth, J. (2019). Empoderamento. São Paulo, SP: Pólen.

Buber, M. (2001). Eu e Tu. São Paulo, SP: Centauro.

Carone, I., \& Bento, M. A. S. (2002). Psicologia social do racismo: estudos sobre branquitude e branqueamento no Brasil. Petrópolis, RJ: Vozes.

Conselho Federal de Psicologia (CREPOP). (2017). Relações Raciais: Referências Técnicas para atuação de psicólogas/os. Brasília, DF: CFP.

Davis, A. (2017). Mulheres, Cultura e Política. São Paulo, SP: Boitempo.

Davis, A. (2018). A liberdade é uma luta constante. São Paulo, SP: Boitempo.

Fadel, F. C., \& Pinheiro, M. E. (2015). Gestalt-Terapia de Grupo: o que é isso? Revista IGT na Rede, 12(22), 196-239. Recuperado de http://pepsic.bvsalud.org/pdf/igt/v12n22/v12n22a08.pdf

Frazão, L., \& Fukumitsu, K. O. (2013). Gestalt-terapia: fundamentos epistemológicos e influências filosóficas. São Paulo, SP: Summus.

Freire, P. (1996). Pedagogia da autonomia: saberes necessários à prática educativa. São Paulo, SP: Paz e Terra. 
Gomes, N. L. (2017). O Movimento Negro Educador: saberes construídos nas lutas por emancipação. Petrópolis, RJ: Vozes.

Gonçalves, R., \& Ambar, G. (2015). A questão racial, a universidade e a (in)consciência negra. Lutas Sociais, São Paulo, 19(34), 202213.

https://revistas.pucsp.br/ls/article/viewFile/25767/pdf

Guimarães, A. S. A. (2003). O acesso de negros às universidades públicas. In P. B. G. Silva \& V. R. Silvério (Eds.), Educação e ações afirmativas entre: a injustiça simbólica e a injustiça econômica (pp. 115-128). Brasília, DF: INEP.

Hernandez, A. R. C., Accorssi, A., \& Guareschi, P. (2013). Psicologia das minorias ativas: por uma psicologia política dissidente. Revista Psicologia Política, 13(27), 383-387. Recuperado de http://pepsic.bvsalud.org/scielo.php?script=sci_arttext\&pid=S1 519-549X2013000200012\&lng =pt\&tlng=pt

Hooks, B. (1994). Living to love (1993). In E. C. White (Ed.), The Black women's health book (pp. 231-236). Seattle: Seal Press.

Hooks, B. (2006). Love as the practice of freedom. In B. Hooks (Ed.), Outlaw Culture. Resisting Representations (pp. 289-298). New York: Routledge.

Hycner, R., \& Jacobs, L. (1997). Relação e Cura em Gestalt-terapia. São Paulo, SP: Summus.

Kilomba, G. (2010). "The Mask". Plantation Memories: Episodes of Everyday Racism. Münster: Unrest Verlag.

Mbembe, A. (2018). Necropolítica: Biopoder, soberania, estado de exceção. Política da morte. São Paulo, SP: N-1 Edições.

Moreira, A. (2018). O que é racismo recreativo? Belo Horizonte, MG: Letramento.

Nogueira, R. (2011a). Denegrindo a Filosofia: O pensamento como coreografia de conceitos afroperspectivistas. Revista de Filosofia, 4(2), 1-19. doi: 10.31977/grirfi.v4i2.500

Nogueira, R. (2011b). Ubuntu Como Modo de Existir. Revista da Associação Brasileira de Pesquisadores(as) Negros(as), 3(6), 147-150. Recuperado de https://filosofiaafricana.weebly.com/uploads/1/3/2/1/13213792/renato_noguer a_-_ubuntu_como_modo_de_existir.pdf

Oliveira, G. (2008). Relações raciais e a Gestalt-terapia: Contraste no Olhar (Monografia de Conclusão de Curso). Instituto Gestalt de São Paulo, São Paulo, Brasil.

Perls, F., Hefferline, R., \& Goodman, P. (1997). Gestalt-terapia. São Paulo, SP: Summus.

Ribeiro, D. (2017). O que é lugar de fala? Belo Horizonte, MG: Letramento.

Ribeiro. J. P. (1994). Gestalt-Terapia, o processo grupal: uma abordagem fenomenológica da teoria de campo e holística. São Paulo, SP: Summus. 
Souza, N. S. (1983). Tornar-se negro: as vicissitudes de identidade do negro brasileiro em ascensão social. Rio de Janeiro, RJ: Graal.

Tellegen, T. A. (1984). Gestalt e grupos: uma perspectiva sistêmica. São Paulo, SP: Summus.

Veiga, L. M. (2017). Descolonizar a Psicologia: Considerações a uma Psicologia Preta [site]. Recuperado de https://ceert.org.br/noticias/direitoshumanos/20238/descolonizar-a-psicologia-consideracoes-auma-psicologia-preta

Veiga, L. M. (2019). Descolonizando a psicologia: notas para uma Psicologia Preta. Fractal: Revista de Psicologia, 31(1), 244-248. doi: 10.22409/1984-0292/v31i_esp/29000

Yontef, G. M. (1998). Processo, diálogo e awareness: ensaios em Gestalt-terapia. São Paulo, SP: Summus.

\section{Endereço para correspondência \\ Andrea dos Santos Nascimento}

Rua Alma do Tempo, 08 Lt 08 Qd 08, Manguinhos, CEP 29173-005, Serra - ES, Brasil

Endereço eletrônico: andreanas@gmail.com

\section{Gabriela Faria de Souza}

Rua Benedito Melo Serrano, 167, Mata da Praia, CEP 29065-040, Vitória - ES, Brasil

Endereço eletrônico: gabifariadesouza@gmail.com

\section{Maiara da Silva}

Rua Tevio Batista da Silva, 104 apto 203, Segurança do Lar, CEP 29072-380, Vitória - ES, Brasil

Endereço eletrônico: maisilvar@gmail.com

\section{Mário Silva de Oliveira}

Rua 27, 03, Santa Mônica, CEP 29105-470, Vila Velha - ES, Brasil

Endereço eletrônico: marioobl@hotmail.com

Recebido em: 12/10/2019

Reformulado em: 03/01/2020

Aceito em: 06/01/2020

\section{Notas}

* Professora doutora da Universidade Federal do Espírito Santo. Responsável pela disciplina de Gestalt-Terapia. Pesquisadora das áreas de orientação sexual e de gênero, violência contra a mulher, cultura e negritude brasileira.

** Psicóloga clínica. Formação pelo Instituto de Gestalt de São Paulo em andamento.

*** Graduanda do $8^{\circ}$ período do curso de Psicologia pela UFES. Atua como extensionista voluntária no Projeto de Extensão "Gestalt-Terapia, escuta e acolhimento psicológico de grupos".

**** Graduação em Teologia. Estudante de Psicologia. Especialização em Gestão e Políticas e Segurança Pública. Atua como voluntário no Projeto de Extensão "Gestalt-Terapia, escuta e acolhimento psicológico de grupos". 
1 Em 2017 foram selecionados para extensionistas um estudante branco e uma estudante negra para a atividade no ano seguinte. $O$ estudante branco foi um dos idealizadores do projeto, entretanto seu desejo, assim como o da coordenadora, era que os dois facilitadores do grupo fossem pessoas negras. Esse aluno só aceitou ser extensionista após uma, das duas vagas, não ter sido preenchida por outra pessoa negra, havendo, portanto, uma vaga disponível. Ao final de 2018 para exercício em 2019, foram selecionados dois estudantes negros retintos, sendo um do sexo masculino e outro do sexo feminino.

2 Tássia Reis. (2016). Da Lama / Afrontamento (part. Stefanie). Outra Esfera. São Paulo: Tássia Reis / Independente.

Este artigo de revista Estudos e Pesquisas em Psicologia é licenciado sob uma Licença Creative Commons Atribuição-Não Comercial 3.0 Não Adaptada. 